Check for updates

Cite this: RSC Adv., 2017, 7, 45582

Received 11th July 2017

Accepted 19th September 2017

DOI: $10.1039 / c 7 r a 07637 a$

rsc.li/rsc-advances

\section{Synthesis, structures and magnetic properties of isoreticular polyrotaxane-type two-dimensional coordination polymers $\uparrow$}

\author{
In-Hyeok Park, (D) ac Tun Seng Herng, (DD bc Huiyeong Ju, (D) a Jun Ding, (D) *c \\ Shim Sung Lee (iD *a and Jagadese J. Vittal (D) *c
}

\begin{abstract}
Two isoreticular polyrotaxane-type two-dimensional coordination polymers (2D CPs) $\left[\mathrm{Co}_{2}(\mathrm{bpy})(\mathrm{sdb})_{2}\right]$. $2 \mathrm{H}_{2} \mathrm{O}$ (1) and $\left[\mathrm{CO}_{2}(\mathrm{bpe})(\mathrm{sdb})_{2}\right] \cdot \mathrm{DMA} \cdot 1.5 \mathrm{H}_{2} \mathrm{O}$ (2) (where $\mathrm{sdb}=4,4^{\prime}$-sulfonyldibenzoate; bpy $=4,4^{\prime}$ bipyridyl and bpe $=4,4^{\prime}$-bipyridyl ethylene) have been synthesized and their solid state structures have been determined by X-ray crystallography. The solid state structures made up of wheels and axles have been synthesized using a bent dicarboxylate (sdb), two linear spacer ligands and Co(॥). Interestingly, the sheets are two-fold entangled by $\left[\mathrm{CO}_{2}(\mathrm{sdb})_{2} \mathrm{CO}_{2}\right]$ wheels and bpy or bpe axles. Due to the shorter length of the bpy ligand, the $\left[\mathrm{CO}_{2}(\mathrm{sdb})_{4}\right]$ moieties in 1 are brought closer than in the sheet formed in 2 . The magnetic properties of 1 and 2 have been discussed and fitted according to a spin Hamiltonian. 1 showed predominantly antiferromagnetic interactions with exchange integral of $-1.522 \mathrm{~cm}^{-1}$. While 2 exhibited the paramagnetic behaviour below $40 \mathrm{~K}$ and antiferromagnetic behaviour at higher temperature.
\end{abstract}

\section{Introduction}

Coordination polymers (CPs) are a class of highly crystalline materials formed by metal ions or metal clusters with exodentate spacer ligands. ${ }^{1,2}$ One, two and three-dimensional CPs can be designed to exhibit high surface area, porosity, optical and magnetic properties. ${ }^{3-7}$ Among these, polyrotaxane structures can be designed from wheels formed by two bent spacer ligands with two metal ions and axles from linear spacer coligands. $^{8-18}$ For instance, the two-dimensional (2D) CPs containing polyrotaxane structures can be designed and constructed from bent dipyridyl ligands and linear dicarboxylates or vice versa. ${ }^{19-25}$ Recently, we reported several supramolecular isomers in polyrotaxane-type CPs of $\mathrm{Zn}$ (II) and $\mathrm{Co}(\mathrm{II})$ using a bent ligand, 4,4'-sulfonyldibenzoate (sdb, Scheme 1) and a long linear spacer ligand, 1,4-bis[2-(4'-pyridyl)ethenyl]benzene (bpeb). ${ }^{26,27}$ The polyrotaxane-type Co(II) CPs show typically antiferromagnetic behaviour due to the long spacer ligand bpeb which prevents the neighbouring paddlewheel $\mathrm{Co}$ (II) coming closer in the solid state structures. Hence we have employed shorter bipyridyl spacer ligands namely 4,4'-bipyridyl (bpy) and

${ }^{a}$ Department of Chemistry and Research Institute of Natural Science, Gyeongsang National University, Jinju 52828, South Korea. E-mail: sslee@gnu.ac.kr

${ }^{b}$ Department of Materials Science and Engineering, National University of Singapore, 119260, Singapore.E-mail: msedingj@nus.edu.sg

'Department of Chemistry, National University of Singapore, 3 Science Drive 3, 117543, Singapore. E-mail: chmijv@nus.edu.sg

$\dagger$ Electronic supplementary information (ESI) available: PXRD patterns, TGA and crystal data. CCDC 1551657 and 1551656. For ESI and crystallographic data in CIF or other electronic format see DOI: 10.1039/c7ra07637a 4,4'-bipyridyl ethylene (bpe) to synthesize similar polyrotaxane CPs and investigated their magnetic behaviour (Scheme 1). The details are given below.

\section{Results and discussion}

The single crystals of $\left[\mathrm{Co}_{2}(\mathrm{bpy})(\mathrm{sdb})_{2}\right] \cdot 2 \mathrm{H}_{2} \mathrm{O}(\mathbf{1})$ and $\left[\mathrm{Co}_{2}(-\right.$ bpe)(sdb $\left.)_{2}\right] \cdot \mathrm{DMA} \cdot 1.5 \mathrm{H}_{2} \mathrm{O}$ (2) were synthesized by the

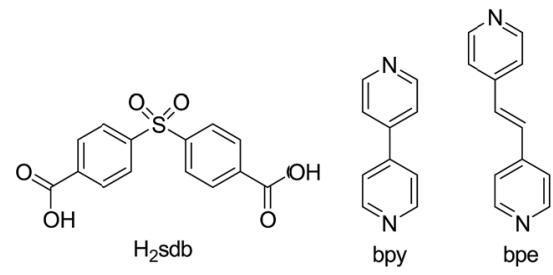

(a)

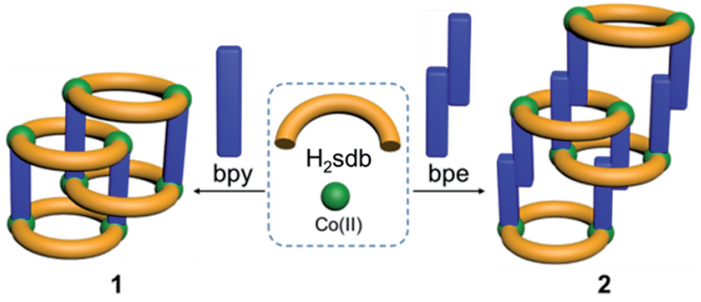

(b)

Scheme 1 (a) Structural diagrams of $\mathrm{H}_{2} \mathrm{sdb}$, bpy and bpe. (b) Polyrotaxane structures ( 1 and 2 ) formed from these two ligands with Co(II). 
solvothermal reactions of $\mathrm{Co}\left(\mathrm{NO}_{3}\right)_{2} \cdot 6 \mathrm{H}_{2} \mathrm{O}$ and $\mathrm{H}_{2}$ sdb with bpy or bpe, respectively, in the equimolar ratio in the mixtures of dimethylformamide (DMF) or dimethylacetamide (DMA)/ dimethylsulfoxide (DMSO)/water at $120{ }^{\circ} \mathrm{C}$. The two isoreticular polyrotaxane-type $2 \mathrm{D}$ CPs $(\mathbf{1}$ and 2$)$ are constructed from the paddlewheel repeating unit $\left[\mathrm{Co}_{2}\left(\mathrm{O}_{2} \mathrm{C}-\mathrm{C}\right)_{4}\right]$. The adjacent paddlewheel units are bridged by two sdb ligands to form a ring, $\left[\mathrm{CO}_{2}(\mathrm{sdb})_{2} \mathrm{Co}_{2}\right]$ thus generates a one-dimensional (1D) structure. These chains are further connected by the bpy or bpe spacer ligands in the axial positions of the paddlewheel units yielding $2 \mathrm{D}$ CPs. Interestingly, the $\left[\mathrm{Co}_{2}(\mathrm{sdb})_{2} \mathrm{Co}_{2}\right]$ rings and bpy (1) or bpe (2) axles from the neighbouring 2D structures produced polyrotaxane structures. The bulk homogeneity of the both products was confirmed by PXRD patterns (Fig. S1 and $\mathrm{S} 2 \dagger)$. The details of the individual structures are described below.

\section{$\left[\mathrm{Co}_{2}(\mathrm{bpy})(\mathrm{sdb})_{2}\right] \cdot 2 \mathrm{H}_{2} \mathrm{O}(\mathbf{1})$}

Blue blocks of single crystals of $\left[\mathrm{Co}_{2}(\mathrm{bpy})(\mathrm{sdb})_{2}\right] \cdot 2 \mathrm{H}_{2} \mathrm{O}(\mathbf{1})$ crystallized in orthorhombic space group $\mathrm{Cmcm}$ with $Z=4$ and the asymmetric unit contains quarter of the formula unit. In the crystal structure of $\mathbf{1}$ (Fig. 1), the atoms $\mathrm{Co} 1, \mathrm{Co} 2, \mathrm{~N} 1, \mathrm{C} 3, \mathrm{C} 4$ and $\mathrm{N} 2$ have crystallographic $m 2 m$ symmetry and the other $\mathrm{C}$ atoms in the bpy ligand occupy crystallographic $m$ plane. The paddlewheel is produced by applying this $m 2 m$ operation (Fig. 1a). Two sdb ligands are bonded to two neighbouring paddlewheels along $a$-axis forming $\mathrm{Co}_{2}(\mathrm{sdb})_{2}$ ring (Fig. 1b). The Co-Co diagonal distance in this ring, $12.737 \AA$ corresponds to the length $a$ of the unit cell. The axial positions are occupied by bpy ligands which are along the crystallographic $b$-axis. The distance of the Co-bpy-Co $\cdots$ Co repeating unit, $13.765 \AA$ is the length $b$ of unit cell. The connectivity of $\mathrm{Co}_{2}(\mathrm{bpy})(\mathrm{sdb})_{2}$ produced a $2 \mathrm{D}$ structure in $a b$-plane with $\mathrm{S} 1, \mathrm{O} 3$ and $\mathrm{O} 4$ atoms sit on crystallographic $m$ plane. Two-fold entanglement of these rings formed by $\mathrm{Co}_{2}(\mathrm{sdb})_{2}$ with dimension, $8.59 \AA \times 8.59 \AA$ (the distances between centres of $\mathrm{Co}(\mathrm{II})$ and $\mathrm{S} \cdots \mathrm{S}$ distances in the ring) by the axle bpy ligands from the neighbouring 2D structure generates a polyrotaxane structure (Fig. 1c-f). This polyrotaxane entanglement has been observed in several 2D structures before. ${ }^{8-27}$ By virtue of X-ray crystallographic symmetry, bpy ligand is at the centre of this square cavity. The total potential solvent accessible area volume as calculated by PLATON in 1 is $288.3 \AA^{3}$ which is $7.6 \%$ of the unit cell volume $3809.5 \AA^{3}$ despite two-fold interpenetration. ${ }^{28-30}$

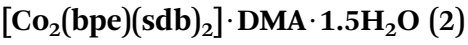

The dark violet block-shaped single crystals of $\left[\mathrm{Co}_{2}(\mathrm{bpe})(\mathrm{sdb})_{2}\right]$. DMA $1.5 \mathrm{H}_{2} \mathrm{O}(2)$ crystallized in monoclinic space group $P 2_{1} / c$ with $Z=4$. Similar to 1 , the structure of 2 also adopts a doublyentangled 2D structure (Fig. 2). The asymmetric unit contains a formula unit. The coordination mode at the $\mathrm{Co}(\mathrm{II})$ centre is square-pyramid with four oxygen atoms from four sdb ligands in the square-plane and one nitrogen atom of the bpe ligand at the apical position. The paddlewheel repeating units are connected to four sdb ligands and propagate along the $c$-axis via $\mathrm{Co}_{2}(\mathrm{sdb})_{2}$ ring to form a $1 \mathrm{D}$ polymeric structure (Fig. 2a-c). The

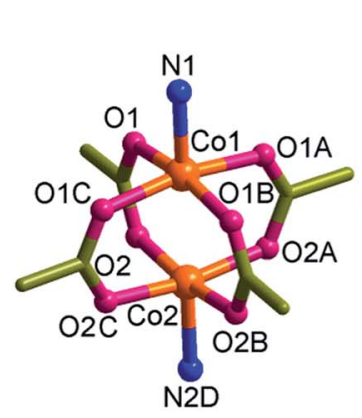

(a)

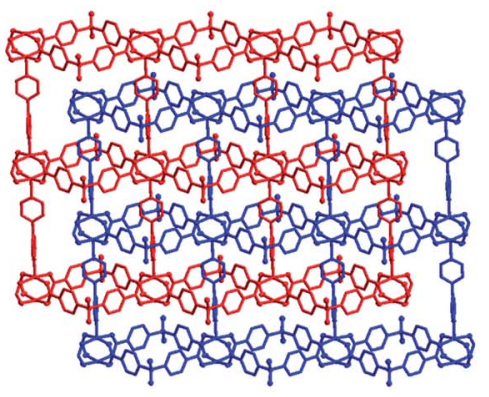

(d)

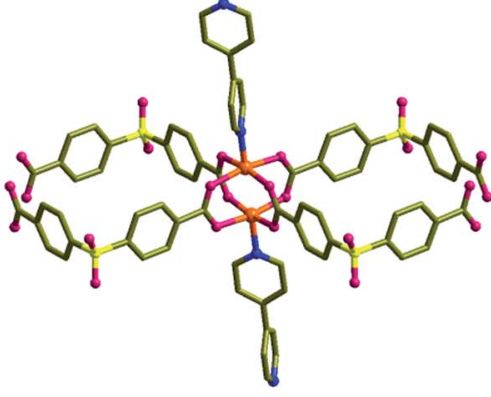

(b)

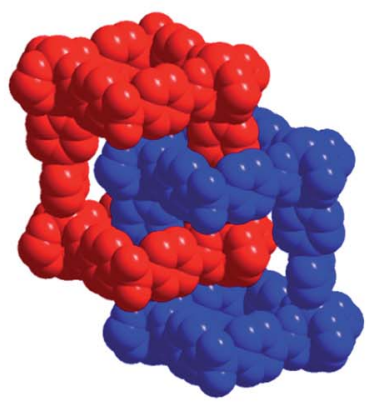

(e)

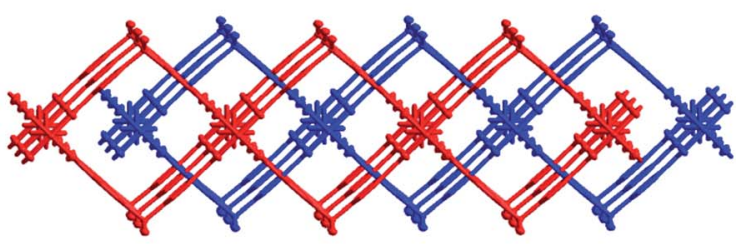

(c)

Fig. $12 \mathrm{D}$ grid-type polyrotaxane of $\left[\mathrm{CO}_{2}(\mathrm{bpy})(\mathrm{sdb})_{2}\right] \cdot 2 \mathrm{H}_{2} \mathrm{O}$ (1). (a) Coordination environment of Co(॥) atoms. Symmetry codes: (A) $1-x, y, z$; (B) $1-x, y, 1 / 2-z$; (C) $x, y, 1 / 2-z$; (D) $x,-1+y, z$. (b) Basic building unit. (c) Top view. (d) The 2-fold entanglement showing the 2D square-type grids. (e) and (f) Rotaxane units. 


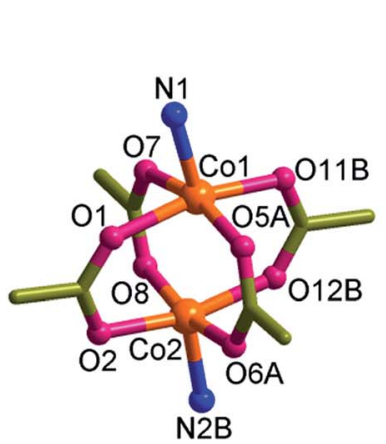

(a)

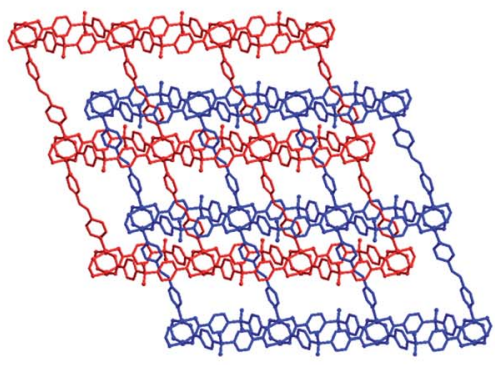

(d)

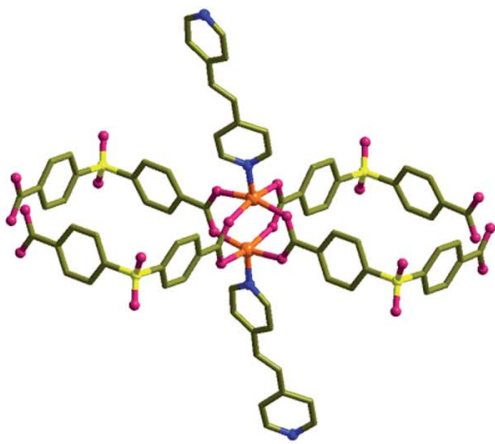

(b)

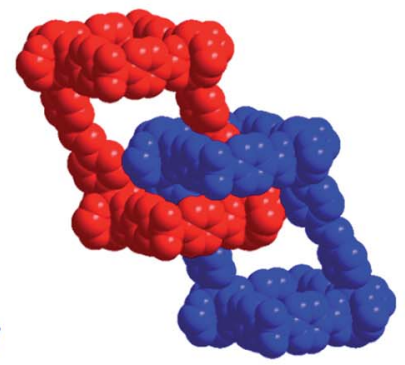

(e)

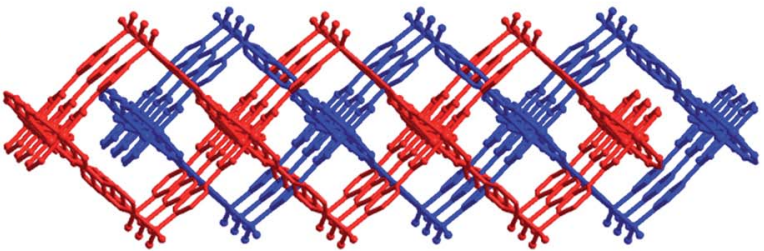

(c)

Fig. 2 2D polyrotaxane structure of $\left[\mathrm{CO}_{2}(\mathrm{bpe})(\mathrm{sdb})_{2}\right] \cdot \mathrm{DMA} \cdot 1.5 \mathrm{H}_{2} \mathrm{O}$ (2). (a) A view showing the environment of Co(॥) atoms. Symmetry codes: (A) $x, y, 1+z$; (B) $x-1, y, z$. (b) Basic building unit. (c) Top view. (d) The 2-fold entanglement of the 2D parallelogram grids. (e) and (f) Rotaxane units.

square cavity has dimension of $8.58 \AA \times 8.61 \AA$ (the distances between centres of $\mathrm{Co}(\mathrm{II})$ and $\mathrm{S} \cdots \mathrm{S}$ distances in the ring) producing a 1D structure with square cavities due to the use of bent sdb ligand. The bpe ligand also acts as a pillar to this 1D structure to produce the layered structure (Fig. 2d) with crystallographic glide plane and inversion centre.

Like 1, the linear bpe ligand also penetrates the $\left[\mathrm{Co}_{2}(\mathrm{sdb})_{2}\right]$ square ring to form a rotaxane structure in the $2 \mathrm{D}$ grid of 2 . The pyridyl ring of bpe ligand is occupied in the cavity centre of the square ring. Again, the unusual entanglement of polyrotaxane was generated by rotaxane arrangement in 2 . The total potential solvent area volume as calculated by PLATON in 2 is $874.6 \AA^{3}$ which is $20.2 \%$ of the unit cell volume $4327.7 \AA^{3}$ despite twofold interpenetration (Fig. $2 \mathrm{~d}-\mathrm{f}$ ). ${ }^{28-30}$ The void volume was partially occupied by one DMF and one and half water molecules. Unlike 1 showing a square-type grid (Fig. 1d), the 2D parallelogram grid in 2 (Fig. $2 \mathrm{~d}$ ) is generated from the distortion of the paddlewheel structure (Fig. 2a) and the longer length of the bpe spacer ligand.

\section{Magnetic properties}

As shown in Fig. 3, 1 and 2 display very contrast $\chi_{\mathrm{m}} T$ behaviour. For $1, \chi_{\mathrm{m}} T$ increases drastically from $0.27 \mathrm{~cm}^{3} \mathrm{~K} \mathrm{~mol}^{-1}$ at $2 \mathrm{~K}$ to $3.08 \mathrm{~cm}^{3} \mathrm{~K} \mathrm{~mol}^{-1}$ at $50 \mathrm{~K}$. Above $50 \mathrm{~K}, \chi_{\mathrm{m}} T$ of these samples increases monotonically with increasing temperature. Such $\chi_{\mathrm{m}} T$ reduction at low temperature may associate with the presence of antiferromagnetic exchange coupling between the Co(II) ions and/or to the depopulation of the higher energy
Kramers doublets of the Co(II) centres with a $4 T 1$ term as the ground state. At room temperature ( $300 \mathrm{~K}), 1$ exhibits $\chi_{\mathrm{m}} T$ value of $3.54 \mathrm{~cm}^{3} \mathrm{~K} \mathrm{~mol}^{-1}$ that is higher than expected $1.87 \mathrm{~cm}^{3} \mathrm{~K} \mathrm{~mol}^{-1}$ for spin only high spin $\operatorname{Co}(\mathrm{II})$ ions $(S=3 / 2$ and $g=2)$ and it is closed to the theoretical value $\left(\sim 3.3 \mathrm{~cm}^{3} \mathrm{~K} \mathrm{~mol}^{-1}\right)$ of spin-orbital coupling of $\mathrm{Co}(\mathrm{II})$ ions. Thus, this phenomenon may be attributed to the spin-orbital coupling of $\mathrm{Co}(\mathrm{II})$ ions.

For 2, the value of $\chi_{\mathrm{m}} T$ remains nearly constant from $2 \mathrm{~K}$ up to $40 \mathrm{~K}$, suggesting the paramagnetic behaviour. Then the $\chi_{\mathrm{m}} T$ increases monotonically with increasing temperature with $\chi_{\mathrm{m}} T$

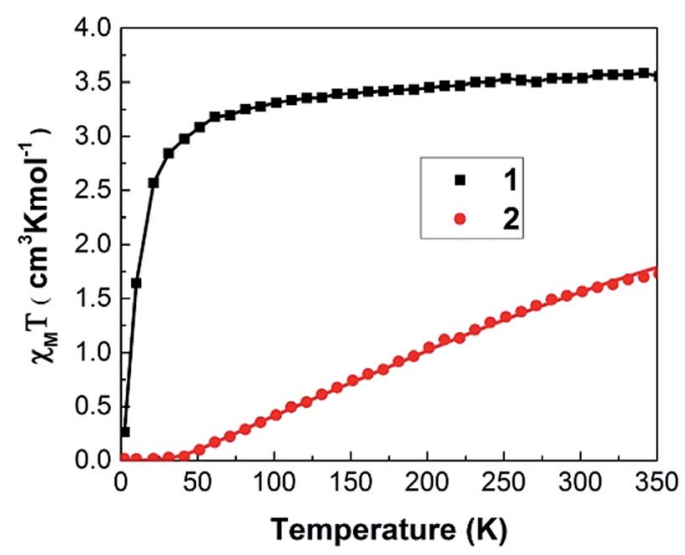

Fig. 3 Temperature dependence of $\chi_{\mathrm{m}} T$ for 1 and 2 measured at 500 Oe from 2 to $350 \mathrm{~K}$. The samples are fitted according to a spin Hamiltonian by the PHI program with $g=1.91$ for 1 and 2.02 for 2 (solid lines). 
of $1.56 \mathrm{~cm}^{3} \mathrm{~K} \mathrm{~mol}^{-1}$ at $300 \mathrm{~K}$. This phenomenon suggests the presence of antiferromagnetic exchange coupling in the CP with increasing temperature. ${ }^{32,33}$ It is noted that the value of $\chi_{\mathrm{m}} T$, $1.56 \mathrm{~cm}^{3} \mathrm{~K} \mathrm{~mol}^{-1}$ at $300 \mathrm{~K}$ is same order of magnitude as the expected $1.87 \mathrm{~cm}^{3} \mathrm{~K} \mathrm{~mol}^{-1}$ for spin only high spin Co(II) ions ( $S$ $=3 / 2$ and $g=2$ ). Thus, magnetic properties of 2 mainly predominated by high spin Co(II) ions.

The magnetic susceptibility data were fitted according to a spin Hamiltonian by the $\mathrm{PHI}^{31}$ program with $g=1.91$ for 1 and 2.02 for 2 in the temperature range of $2-350 \mathrm{~K}$. The best fitted data yielded the exchange integral $\mathrm{J}$ of $-1.522 \mathrm{~cm}^{-1}$ for 1 and $-61.281 \mathrm{~cm}^{-1}$ for 2 respectively. Both samples exhibit a temperature independent paramagnetic (TIP) component of $5.0 \times 10^{-4} \mathrm{~cm}^{3} \mathrm{~K} \mathrm{~mol}^{-1}$. These results indicate that antiferromagnetic interaction exists within the Co(II) dimer unit ${ }^{31,32} \mathbf{1}$ and 2 shows axial zero field splitting (ZFS) parameter $(D)$ of 4.69 and $4.49 \mathrm{~cm}^{-1}$, respectively, with the rhombic ZFS parameter $(E)$ of $\pm 0.056 \mathrm{~cm}^{-1}$. The values of the parameters $g, D$ and $E$ indicate the presence of magnetic anisotropy as expected for the tetrahedrally coordinated $\mathrm{Co}(\mathrm{II})$ atom. ${ }^{34}$

In summary we synthesized two isoreticular pillared-layer $2 \mathrm{D}$ CPs (1 and 2) of $\mathrm{Co}(\mathrm{II})$ with sdb and two linear bipyridyl spacer ligands with different lengths, bpy and bpe, forming polyrotaxane-type structures. The separation between the $\left[\mathrm{Co}_{2}(\mathrm{sdb})_{2}\right]$ layers has been varied due to the difference in lengths of the spacer ligands. Hence the variable temperature magnetic properties have been investigated for $\mathbf{1}$ and $\mathbf{2}$ which reflects the interplays between structural properties of samples and their magnetic behaviours.

\section{Experimental}

\section{General}

All chemicals were purchased from commercial sources and used as received. All solvents used were of reagent grade. Elemental analyses were carried out on a LECO CHNS-932 elemental analyzer. Thermogravimetric analyses were recorded in a TA Instruments TGA-Q50 thermogravimetric analyzer. Samples were heated at a constant rate of $5{ }^{\circ} \mathrm{C} \mathrm{min}^{-1}$ from room temperature to $700{ }^{\circ} \mathrm{C}$ and at a continuous flow nitrogen atmosphere. The FT-IR spectra were recorded using Thermo Fisher Scientific Nicolet is 10 FT-IR spectrometer with $\mathrm{KBr}$ pellets. Powder X-ray diffraction (PXRD) patterns were recorded usning Bruker D8 DISCOVER.

\section{Preparation of $\left[\mathrm{Co}_{2}(\mathrm{bpy})(\mathrm{sdb})_{2}\right] \cdot 2 \mathrm{H}_{2} \mathrm{O}(1)$}

A mixture of bpy (11.1 mg, $0.071 \mathrm{mmol}), \mathrm{H}_{2} \mathrm{sdb}(22.1 \mathrm{mg}, 0.072$ $\mathrm{mmol})$ and $\mathrm{Co}\left(\mathrm{NO}_{3}\right)_{2} \cdot 6 \mathrm{H}_{2} \mathrm{O}(21.0 \mathrm{mg}, 0.072 \mathrm{mmol})$ dissolved in DMF $(3 \mathrm{~mL}), \mathrm{H}_{2} \mathrm{O}(1 \mathrm{~mL})$ and DMSO $(0.5 \mathrm{~mL})$ was placed in a $5 \mathrm{~mL}$ glass tube, and then 2-3 drops of $0.1 \mathrm{M} \mathrm{NaOH}$ solution was added. The tube was sealed and kept at $120^{\circ} \mathrm{C}$ for $48 \mathrm{~h}$, followed by cooling to room temperature over $8 \mathrm{~h}$. Dark blue block-shaped crystals 1 suitable for single crystal X-ray diffraction (SC-XRD) analysis were obtained. Yield: 70\%. Anal. calcd for $\left[\mathrm{C}_{38} \mathrm{H}_{27} \mathrm{Co}_{2} \mathrm{~N}_{2} \mathrm{O}_{13.5} \mathrm{~S}_{2}\right]$ : C, 50.18; H, 2.99; N, 3.08; S, 7.05. Found: C, 50.15; H, 2.99; N, 3.20; S, 7.12\%. IR (KBr pellet, $\left.\mathrm{cm}^{-1}\right)$
3432, 3093, 3061, 1629, 1568, 1490, 1409, 1326, 1301, 1217, 1169, 1138, 1101, 1071, 1015, 845, 812, 779, 723, 695, 618 and 584.

\section{Preparation of $\left[\mathrm{Co}_{2}(\mathrm{bpe})(\mathrm{sdb})_{2}\right] \cdot \mathrm{DMA} \cdot 1.5 \mathrm{H}_{2} \mathrm{O}(2)$}

A mixture of bpe $(13.0 \mathrm{mg}, 0.071 \mathrm{mmol}), \mathrm{H}_{2} \mathrm{sdb}(21.9 \mathrm{mg}$, $0.071 \mathrm{mmol})$ and $\mathrm{Co}\left(\mathrm{NO}_{3}\right)_{2} \cdot 6 \mathrm{H}_{2} \mathrm{O}(20.8 \mathrm{mg}, 0.071 \mathrm{mmol})$ dissolved in DMA ( $3 \mathrm{~mL}), \mathrm{H}_{2} \mathrm{O}(1 \mathrm{~mL})$ and DMSO $(0.5 \mathrm{~mL})$ was placed in a $5 \mathrm{~mL}$ glass tube, and then 2-3 drops of $0.1 \mathrm{M} \mathrm{NaOH}$ solution was added. The tube was sealed and kept at $120^{\circ} \mathrm{C}$ for $48 \mathrm{~h}$, followed by cooling to room temperature over $8 \mathrm{~h}$. Dark blue block-shaped crystals 2 suitable for SC-XRD analysis were obtained. Yield: $80 \%$. Anal. calcd for $\left[\mathrm{C}_{43} \mathrm{H}_{35} \mathrm{Co}_{2} \mathrm{~N}_{3} \mathrm{O}_{14} \mathrm{~S}_{2}\right]$ : C, 51.66; H, 3.53; N, 4.20; S, 6.41. Found: C, 51.82; H, 3.39; N, 4.27; $\mathrm{S}, 6.51 \%$. IR (KBr pellet, $\mathrm{cm}^{-1}$ ) 3401, 3095, 3044, 1635, 1612, 1569, 1490, 1409, 1328, 1301, 1169, 1138, 1101, 1070, 1029, 1016, 844, 779, 739, 696, 618 and 551.

\section{Crystallographic structure determinations}

Crystal data for 1 and 2 at $173 \mathrm{~K}$ were collected on a Bruker SMART APEX II ULTRA diffractometer equipped with graphite monochromated Mo $\mathrm{K} \alpha$ radiation $(\lambda=0.71073 \AA)$ generated by a rotating anode. The cell parameters for the compounds were obtained from a least-squares refinement of the spot (from 36 collected frames). Data collection, data reduction and absorption correction were carried out using the software package of APEX2. ${ }^{35}$ All of the calculations for the structure determination were carried out using the SHELXTL package. ${ }^{36}$ Relevant crystal data collection and refinement data for the crystal structures of 1 and 2 are summarized in Table S1.† CCDC 1551657 (1) and 1551656 (2) contain the supplementary crystallographic data for this paper. $\dagger$

Crystal 1. Hydrogen atoms on lattice water were not added. Although very high $R$-factors were observed, the connectivity in the $3 \mathrm{D}$ structure is proved beyond any doubt. Surprisingly the crystal structure of this paddlewheel based pillared-layer structure has higher crystallographic symmetry $(\mathrm{Cmcm}$ with $Z$ $=4$ ) than the simple paddlewheel structure observed in $\left[\mathrm{Cu}_{2}(\mathrm{OAc})_{4}\left(\mathrm{H}_{2} \mathrm{O}\right)_{2}\right](C 2 / c$ with $Z=4) .^{37}$

Crystal 2. One pyridyl group in bpe was disordered along the ligand axis and the occupancy was refined to $0.77(1)$. Further one disordered DMA and 1.5 disordered and scattered water molecules were found in the voids. Since the thermal parameters of the atoms of the DMA molecule was not satisfactory, we have resorted to SQUEEZE program. The final agreement factors were better and hence retained.

\section{Magnetic studies}

A superconducting quantum interference device (SQUID) magnetometer MPMS was used for the magnetic characterization. Powder sample with a weight of 5-10 $\mathrm{mg}$ was sealed in a plastic capsule. Magnetic moment was measured in the temperature range of $2 \mathrm{~K}$ to $350 \mathrm{~K}$. The empty plastic capsule exhibited diamagnetism and its magnetic moment was measured for correction. After correction of diamagnetic signal of plastic capsule and sample holder, diamagnetism of 
monomer and paramagnetic contamination (for example free radical), magnetic susceptibility was fitted using the $\mathrm{PHI}^{31}$ program by means of an isotropic spin Hamiltonian ( $\mathrm{SH}$ ) accounting for the exchange coupling (Heisonberg-Dirac-van Vleck Hamitonian) and zero-field splitting (ZFC).

$$
\begin{gathered}
H=H_{\mathrm{ex}}+H_{\mathrm{Zee}}+H_{\mathrm{CF}} \\
H_{\mathrm{ex}}=-2 J_{12}{\overrightarrow{S_{1}}}_{\vec{S}_{2}} \\
H_{\mathrm{Zee}}=\mu_{\mathrm{B}} \sum_{i=1}^{2} \vec{S}_{i} g_{i} \vec{B} \\
H_{\mathrm{CF}}=\sum D_{i}\left[S_{z, i}{ }^{2}-\frac{1}{3} S_{i}\left(S_{i}+1\right)+\frac{E_{i}}{D_{i}}\left(S_{x, i}{ }^{2}-S_{y, i}{ }^{2}\right)\right]
\end{gathered}
$$

$D$ : axial ZFS parameter; $F$ : rhombic ZFS parameter; $\vec{S}$ : spin vector; $\vec{B}$ : magnetic field vector; $g$ : $g$-factor; $\mu_{\mathrm{B}}$ : Bohr magneton.

\section{Conflicts of interest}

There are no conflicts to declare.

\section{Acknowledgements}

This work was supported by the NRF (2016R1A2A205918799), South Korea and the Ministry of Education, Singapore (Tier 1 FRC Grant No. R-143-000-678-114). S. S. L. acknowledges the support of the GNU Fund for Professors on Sabbatical Leave (2014).

\section{References}

1 S. R. Batten, S. M. Nevillle and D. R. Turner, Coordination Polymers: Design, Analysis and Application, RSC Publishing, London, 2009.

2 Design and Construction of Coordination Polymers, ed. M.-C. Hong and L. Chen, Wiley, 2009.

3 Metal-Organic Frameworks: Design and Application, ed. L. R. MacGillivray, Wiley, Weinheim, 2010.

4 Functional Metal-Organic Frameworks: Gas Storage, Separation and Catalysis, ed. M. Schröder, Topics in Current Chemistry, 2010, vol. 293.

5 Metal-Organic Frameworks, Applications from Catalysis to Gas Storage, ed. D. Farrusseng, Wiley-VCH, Weinheim, 2011.

6 Metal Organic Frameworks as Heterogeneous Catalysts, ed. F. L. i. Xamena and J. Gascon, RSC, 2013.

7 Coordination Polymers and Metal Organic Frameworks: Properties, Types, and Applications (Chemical Engineering Methods and Technology), ed. O. L. Ortiz and L. D. Ramirez, Nova Science Publishers Inc, New York, 2012.

8 H. Ju, E. Lee, S. Kim, I.-H. Park, J.-H. Lee and S. S. Lee, CrystEngComm, 2016, 18, 2621.
9 Y. Bu, F. Jiang, K. Zhou, Y. Gai and M. Hong, CrystEngComm, 2014, 16, 1249.

10 J.-Q. Liu, J. Wu, Y.-Y. Wang, J.-Y. Lin and H. Skiyama, CrystEngComm, 2014, 16, 3103.

11 J. Wu, J.-Q. Liu, Y.-Y. Wang, Z.-P. Gou, D.-H. Xu and H. Skiyama, Inorg. Chem. Commun., 2012, 25, 10.

12 J. Yang, J. F. Ma, S. R. Batten and Z. M. Su, Chem. Commun., 2008, 2233.

13 H. Chen, D. Xiao, J. He, Z. Li, G. Zhang, D. Sun, R. Yuan, E. Wang and Q.-L. Luo, CrystEngComm, 2011, 13, 4988.

14 H. Wu, H. Y. Liu, B. Liu, J. Yang, Y. Y. Liu, J. F. Ma, Y. Y. Liu and H. Y. Bai, CrystEngComm, 2011, 13, 3402.

15 F. Luo, Y. T. Yang, Y. X. Che and J. M. Zheng, CrystEngComm, 2008, 10, 981.

16 Y. Q. Lan, S. L. Li, J. S. Qin, D. Y. Du, X. L. Wang, Z. M. Su and Q. Fu, Inorg. Chem., 2008, 47, 10600.

17 S. R. Batten, CrystEngComm, 2001, 18, 1.

18 S. R. Batten and R. Robson, Angew. Chem., Int. Ed., 1998, 37, 1460. 19 X. Guo, Y. Yan, H. Guo, Y. Qi and C. Liu, CrystEngComm, 2016, 18, 2546.

20 M.-D. Zhang, B.-H. Zheng, L. Chen, M.-D. Chen, T. Tao, K. Chen and H. Cao, Dalton Trans., 2016, 45, 3334.

21 L.-L. Liu, C.-X. Yu, F.-J. Ma, Y.-R. Li, J.-J. Han, L. Lin and L.-F. Ma, Dalton Trans., 2015, 44, 1636.

22 Y. Li, X.-Q. Yao, G.-B. Xiao, H.-C. Ma, Y.-X. Yang and J.-C. Liu, J. Mol. Struct., 2015, 1089, 16.

23 S.-L. Wang, F.-L. Hu, J.-Y. Zhou, Y. Zhou, Q. Huang and J.-P. Lang, Cryst. Growth Des., 2015, 15, 4087.

24 H.-D. Guo, Z.-A. Fu, X.-M. Guo, X.-L. Li, R.-Z. Chen, Y.-J. Qi and H.-Y. Zou, J. Mol. Struct., 2013, 1038, 8.

25 Y. Ma, A.-L. Cheng and E.-Q. Gao, Cryst. Growth Des., 2010, 10, 2832.

26 I.-H. Park, R. Medishetty, J.-Y. Kim, S. S. Lee and J. J. Vittal, Angew. Chem., Int. Ed., 2014, 53, 5591.

27 I.-H. Park, H. Ju, T. S. Herng, Y. Kang, S. S. Lee, J. Ding and J. J. Vittal, Cryst. Growth Des., 2016, 16, 7278.

28 A. L. Spek, J. Appl. Crystallogr., 2003, 36, 7.

29 A. L. Spek, Acta Crystallogr., Sect. D: Biol. Crystallogr., 2009, 65, 148.

30 P. van der Sluis and A. L. Spek, Acta Crystallogr., Sect. A: Found. Crystallogr., 1990, 46, 194.

31 N. F. Chilton, R. P. Anderson, L. D. Turner, A. Soncini and K. S. Murray, J. Comput. Chem., 2013, 34, 1164.

32 L. Qin, J.-S. Hu, L.-F. Huang, Y.-Z. Li, Z.-J. Guo and H.-G. Zheng, Cryst. Growth Des., 2010, 10, 4176.

33 N. Benbellat, K. S. Gavrilenko, Y. L. Gal, O. Cador, S. Golhen, A. Gouasmia, J.-M. Fabre and L. Ouahab, Inorg. Chem., 2006, 45, 10440.

34 R. Boča, Coord. Chem. Rev., 2004, 248, 757.

35 Bruker, APEX2 Version 2009.1-0 Data Collection and Processing Software, Bruker AXS Inc., Madison, Wisconsin, U.S.A., 2008.

36 Bruker, SHELXTL-PC Version 6.22 Program for Solution and Refinement of Crystal Structures, Bruker AXS Inc., Madison, Wisconsin, U.S.A, 2001.

37 P. de Meester, S. R. Fletcher and A. C. Skapski, J. Chem. Soc., Dalton Trans., 1973, 2575. 